\title{
Evaluation of Possible Causes of Non-Predatory Mortality of Crustacean Zooplankton in a Small Siberian Reservoir
}

\author{
Olga P. Dubovskaya* \\ Institute of Biophysics of Siberian Branch of Russian Academy of Sciences, \\ Akademgorodok, Krasnoyarsk, 660036 Russia $^{1}$
}

Received 1.09.2007, received in revised form 1.12.2007, accepted 15.01.2008

\begin{abstract}
Non-predatory specific mortality (NPSM) of dominant zooplankton species, Daphnia (longispina group) and Cyclops vicinus, was estimated during 1997-2000 sampling seasons on the basis of a new direct method: live/dead sorting and sediment trap measurements. Simultaneously measured ecological factors, such as water temperature, $\mathrm{pH}$, dissolved oxygen, biomass of cyanobacteria, diatoms, greens and euglens, levels of polyunsaturated fatty acids of $\omega 3$ family, $\alpha$-linolenic (ALA) and eicosapentaenoic (EPA), were considered as possible causes of the mortality using multivariant canonical correlation analysis. Toxicity was discarded on the basis of another set of study of the reservoir. As found, the best predictor of Daphnia mortality was EPA level, negatively correlated with NPSM value. Nevertheless, large part of variance of Daphnia mortality and practically all variance of Cyclops NPSM remain unexplained and need future investigation.
\end{abstract}

Keywords: non-predatory mortality, Daphnia, Cyclops vicinus, ecological factors, canonical correlation analysis.

\section{Introduction}

Dynamics of zooplankton populations are known to be of great importance for overall functioning of aquatic ecosystems. Abundance of zooplankton evidently depends on two factors: growth (somatic and generative) and mortality. Meanwhile, data on mortality are very sparse compare to that of growth due to methodical problems (e.g., Polishchuk and Ghilarov, 1981). Consumption by predators, fish (e.g., Luecke et al., 1990; Hulsmann et al., 1999) and invertebrates (e.g., Razlutskij, 1996; Wojtal et al., 1999) are often the main cause of zooplankton mortality in many locations and seasons. Nevertheless, nonpredatory mortality also can play a determinant role (Luecke et al., 1990; Boersma et al., 1996; Mehner et al., 1998; Dubovskaya et al., 1999; Hulsmann and Weiler, 2000; Hulsmann and Voigt, 2002). In general, causes of non-predatory mortality of zooplankton are believed to be limiting physical and chemical factors, disease, senescence (Velimirov, 1991) and also food (edible phytoplankton) limitation (Luecke et al., 1990; Boersma et al., 1996). However, particular causes of variations of the non-predatory mortality in diverse sites and periods are still unknown. Nonpredatory mortality estimations were indirect and included double error, connected with estimations of birth rate and consumption by fish. Finding of any quantitative correlation of such unreliable

Corresponding author E-mail address: dubovskaya@ibp.krasn.ru

(c) Siberian Federal University. All rights reserved 
value with potentially determinant ecological factors seemed to be doubtful. Since a direct method for measuring of non-predatory specific mortality (NPSM) has been elaborated (Gladyshev et al., 2003a; Dubovskaya et al., 2003), it gives a chance to study particular causes of variations of this type of mortality.

The aim of present study was to evaluate possible causes of seasonal variations of nonpredatory specific mortality of two dominant zooplankton groups in a small Siberian reservoir. Physical (temperature), chemical ( $\mathrm{pH}$, dissolved oxygen) factors and biomass of dominant phytoplankton taxa were considered. As found previously on the basis of a set of biotests, including a standard Daphnia bioassay (Dubovskaya et al., 2002), there was no toxicity in the reservoir during the studied period. Hence, toxicity was excluded from the consideration. Meanwhile, biochemical quality of seston, namely levels of polyunsaturated fatty acids (PUFA) of $\omega 3$ family, which are known to be of importance for zooplankton population dynamics (MullerNavarra, 1995; Gulati and DeMott, 1997; von Elert, 2002; Bec et al., 2003), were also studied as possible factors that influenced the mortality.

\section{Study site, Materials and Methods}

The study was undertaken in a reservoir, locally called as Bugach pond, situated $56^{\circ} 03^{\prime} \mathrm{N}$ and $92^{\circ} 43^{\prime} \mathrm{E}$ in the Bugach river (secondary tributary of the Yenisei River). Its surface area is about $0.32 \mathrm{~km}^{2}$, and its maximum depth is $7 \mathrm{~m}$. Detailed descriptions of the reservoir ecosystem are given elsewhere (Gladyshev et al., 2001, Sushchik et al., 2003). Reservoir was sampled weekly from May to September in 1997-2000 from a site near the middle (station No.1). Samples were taken with an 8-L Ruttner-like sampler and were pooled from depths $1-2 \mathrm{~m}$.
1. Field measurements and sampling

Water temperature and dissolved oxygen were measured with a meter N5221 (MERAELWRO, Poland); $\mathrm{pH}$ was measured using meter "pHep-2" (Hanna Instruments, USA).

Phytoplankton samples of $0.15-0.5 \mathrm{~L}$ volume were filtered through 'Vladipor' filters (Mytischi, Russia) (pore size, 0.75-0.85 $\mu \mathrm{m}$ ). Microalgae were counted and identified under a microscope. To calculate biovolume and wet biomass of algae, they were equated to appropriate geometrical shapes (or their combinations) and relevant sizes were measured using an ocular micrometer (LOMO, St-Petersburg, Russia).

Zooplankton samples (16-32 L) were filtered through a plankton net (mesh size, 0.08 $\mathrm{mm}$ ), stained with aniline blue to distinguish between live and dead organisms (Seepersad and Crippen, 1978; Gladyshev, 1993) and fixed with $10 \%$ formalin. Zooplankton were counted and identified under a microscope.

\section{Fatty acid analysis}

To assay particulate fatty acids (FAs), 100 $\mathrm{mL}$ water samples were first filtered through the $0.08-\mathrm{mm}$ nylon mesh. The seston was then collected from these prescreened water samples by vacuum filtration onto membrane filters 'No.8 Vladipor' (pore size $0.75-0.85 \mu \mathrm{m}$ ) precovered with a layer of $\mathrm{BaSO}_{4}$ to facilitate the separation of residues. The filters were dried at $35{ }^{\circ} \mathrm{C}$ for about $30 \mathrm{~min}$, and the residues then separated from filters, placed into methanol and frozen. Further FA analysis is described in detail elsewhere (Gladyshev et al., 2000). Briefly, lipids were extracted by chloroform-methanol $(2: 1, \mathrm{v} / \mathrm{v})$ three times. After evaporation of the solvent, methyl esters of FAs (FAMEs) were prepared in a mixture of methanol- sulphuric acid $(20: 1, \mathrm{v} / \mathrm{v})$ at $90^{\circ} \mathrm{C}$ for $2 \mathrm{~h}$. The FAMEs were analyzed by gas chromatography-mass spectrometry (GC-MS) using a model GCD Plus (Hewlett-Packard, Palo 
Alto, CA, USA) equipped with a $30 \mathrm{~m} \times 0.25 \mathrm{~mm}$ HP-5 capillary column. The conditions for GC - MS analyses are described in Gladyshev et al. (2000). Identification of FAMEs was achieved by comparing their mass spectra with those in the Hewlett-Packard database and with those of the authentic standards (Sigma, St. Louis, MO, USA).

\section{Mortality estimation}

Non-predatory specific mortality (NPSM) was measured using the method, described by Gladyshev et al. (2003a). Briefly,

$$
m_{i}=\frac{\Delta y_{i}}{\Delta t_{i} \cdot N_{i}}+G_{i} \cdot \frac{y_{i}}{N_{i}}
$$

where $m_{i}$ is non-predatory specific mortality (NPSM, day ${ }^{-1}$ ), $y_{i}$ and $N_{i}$ is the abundance (ind. $\mathrm{m}^{-3}$ ) of dead and alive individuals respectively in sample $i, \Delta t_{i}=t_{i+1}-t_{i}$, with $t_{i}$ (day) being the instant of taking of sample $i, \Delta y_{i}=y_{i+1}-y_{i}$, $G_{i}$ being the specific rate of elimination $\left(\right.$ day $\left.^{-1}\right)$ of dead individuals from the sampled part of the column at the instant $t_{i}$. The specific rate of elimination is calculated as

$$
G_{i}=\frac{v_{i}}{h}
$$

where $v_{i}$ is sinking velocity $\left(\mathrm{m} \cdot \mathrm{day}^{-1}\right)$ of dead individuals, $h$ is the depth of the layer of sampling of $N_{i}$ and $y_{i}$. In this study $h=2 m$ (epilimnion). The sinking velocity, measured by sediment traps, was found to depend on wind speed, $U_{i}, \mathrm{~m} \cdot \mathrm{s}^{-1}$ (Dubovskaya et al., 2003):

$$
v_{i}=3.709 \cdot U_{i}^{-0.984}
$$

\section{Statistical analysis}

Canonical correlation analyses (CCA) was carried out by conventional way (Jeffers, 1981), using STATISTICA 6.0 software (StatSoft, Inc.).

\section{Results}

\section{Physical and chemical factors}

Water temperature (Fig. 1a) had more or less regular pattern of seasonal dynamics with summer oscillations around $20-22^{\circ} \mathrm{C}$, except 1999 , when comparatively cold spring and hot summer occurred. Concentration of dissolved oxygen (Fig. 1b) often exceeded $100 \%$ of saturation and declined down to about $50 \%$ in early June, middle of July and late August. Values of pH (Fig. 1c) were high, except late spring - early summer of 1997-1998.

\section{Phytoplankton}

Cyanobacteria (Fig. 1d) had very high biomass in June-July of 1998 and 2000. During these periods, as well as at the end of August of 1997 and 1999 Aphanizomenon flos-aquae (L.) Ralfs dominated and Anabaena flos-aquae (Lyngb.) Breb. was subdominant. In turn, An. flosaquae dominated at the beginning of August, 1997 and in June-July of 1999, while Aph. flos-aquae was subdominant. At the beginning of August, 2000 Aph. flos-aquae was solo cyanobacterial dominant. In August, 1998, at the end of Julybeginning of August 1999 Microcystis aeruginosa Kutz. emend. Elenk. dominated. In AugustSeptember, 2000 Planktothrix agardhii (Gom.) Anagn. et Kom. dominated.

Biomass of diatoms (Fig. 1e) was very high in spring-early summer, except 1997 when biomass of these algae was negligibly small during all period of the study. In May-June of 1998 and 2000 Stephanodiscus sp. dominated and Cyclotella meneghiniana Kütz. was subdominant, while in the same period of 1999 the opposite ratio of biomass of these species occurred. In August, 1998 C. meneghiniana occurred with very low biomass. At the end of July, 2000 Stephanodiscus sp. appeared and had considerable biomass down to September and C. meneghiniana was subdominant. 


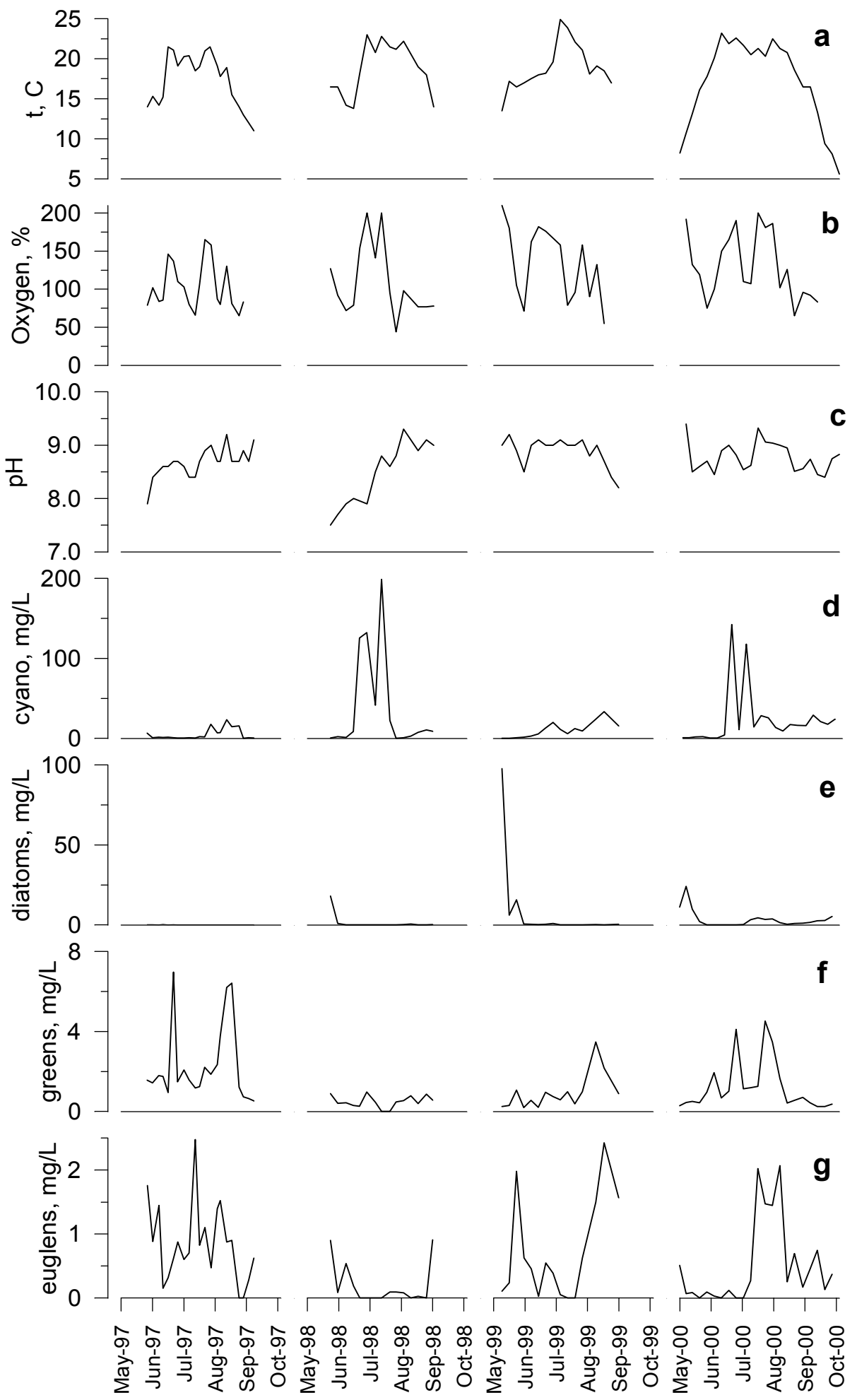

Fig. 1. Ecological factors in the Bugach reservoir (Siberia, Russia), sampling station 1: a - water temperature, $\mathbf{b}$ - dissolved oxygen, $\mathbf{c}$ - $\mathrm{pH}, \mathbf{d}$ - biomass of cyanobacteria, $\mathbf{e}$ - biomass of diatoms, $\mathbf{f}$ - biomass of greens, $\mathbf{g}$ - biomass of euglens 
Green algae (Fig. 1f) had low biomass compare to that of cyanobacteria and diatoms. Two peaks, at the beginning and at the end of summer generally occurred. In June-July of 1997 Scenedesmus acuminatus (Lagerh.) Chod. and Crucigenia tetrapedia (Kirchn.) W. West, G. West dominated and Scenedesmus quadricauda (Turp.) Bréb. was subdominant. At the end of July, in August and in September Scenedesmus bijugatus (Turp.) Kütz. and Chlamydomonas sp. dominated, Sc. acuminatus, Phacotus lenticularis Ehren., C. tetrapedia were subdominant. In 1998 Sc. acuminatus (in June), Pediastrum boryanum (Turp.) Menegh. (in July), Chlamydomonas sp. and Pandorina morum (Müll.) Bory (in August-September) dominated among greens and had comparatively low biomass. In 1999 Chlamydomonas sp. dominated, except the beginning of July when Pandorina morum (Müll.) Bory, Oocystis lacustris Chod. dominated with low biomass. In May, 2000 Sc. acuminatus was dominant, in June - Pediastrum boryanum and Coelastrum microporum Näg., which together with Chlorococcum infusionum (Schrank) Menegh. at one date were dominant not only among greens, but among the total phytoplankton. At the beginning of July, 2000 P. morum dominated, at the end of July and, in August Chlamydomonas sp. was dominant among greens.

Euglens (Fig. 1g) had low biomass compare to the all other taxa, mentioned above. In 1997 Trachelomonas volvocina Ehr. and Phacus pleuronectes (Ehr.) Duj. dominated during all the sampling period, and in one date of June the former was dominant in the total phytoplankton. In 1998 they also were dominant among euglens, and Euglena granulata (Klebs) Schmitz. and Phacus longicauda (Ehr.) Duj. sometimes dominated at the beginning and at the end of sampling season. In 1999 E. granulata dominated down to the middle of August and Euglena proxima Dang. appeared at the end of the season, while Ph. pleuronectes and $T$. volvocina were subdominant. In $2000 E$. proxima was abundant in spring and especially in August, T. volvocina and Lepocinclis ovum (Ehr.) Mink. were subdominant.

\section{Polyunsaturated fatty acids}

Level of 18:3 $\omega 3$, $\alpha$-linoleic acid (ALA), had a mid-summer maximum in 1999 and an AugustSeptember maximum in 2000 (Fig. 2a). Level of 20:5 03 , eicosapentaenoic acid (EPA), in both years of sampling peaked at the beginning and at the end of growing seasons (Fig. 2b).

\section{Zooplankton}

Seasonal dynamics of abundance of dominant zooplankton species - Daphnia cucullata Sars in 1997 and Daphnia longispina O.F.Muller in the other years had irregular patterns (Fig. 2c). NPSM of Daphnia in general was high during periods of low population abundance and low during population increases (Fig. 2d).

The dynamics of abundance of subdominant zooplankton species - adult females of Cyclops vicinus Uljanine, like that of Daphnia, was irregular (Fig. 2e) and NPSM also was high during population declines and low abundance (Fig. 2f).

\section{Canonical correlation analysis}

To reveal possible interactions between studied components of the ecosystem, the multivariant statistical technique, canonical correlation analysis, was used. Firstly, correlations of nonpredatory specific mortality of Daphnia and Cyclops as dependent variables (right set) with water temperature, $\mathrm{pH}$, concentration of dissolved oxygen, biomass of cyanobacteria, diatoms, greens and euglens as independent variables (left set) for the sampling periods of 1997-2000 (correlation matrix No. 1) were analyzed using CCA. Low percentage of total variance extracted indicated comparatively low relationship between these two sets of variables. Moreover, canonical correlation coefficient, $\mathrm{R}_{1}$, pertained to the first canonical root, 


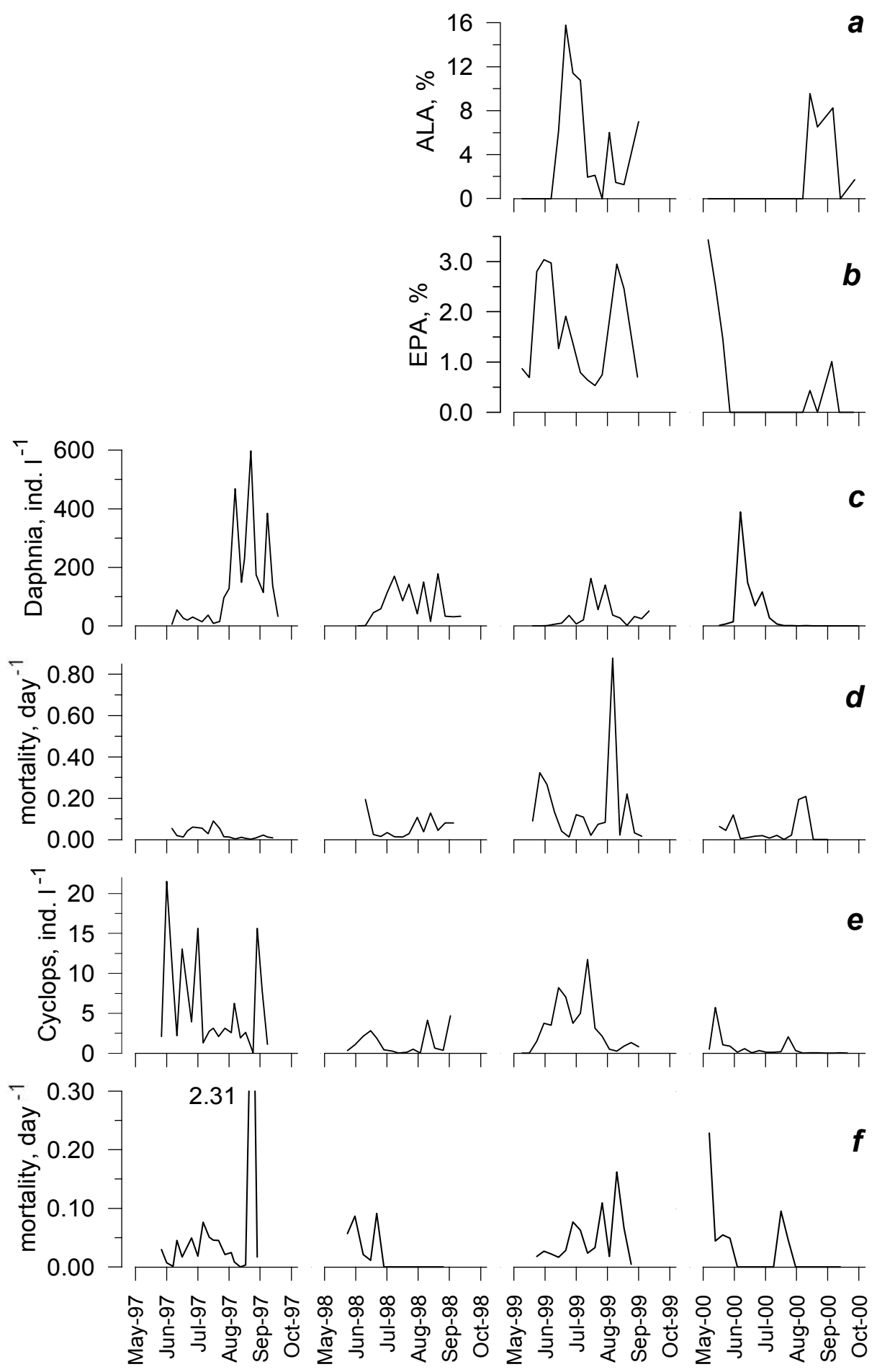

Fig. 2. Dynamics of levels of polyunsaturated fatty acids (as \% of the total fatty acids) in seston and characteristics of dominant zooplankton species in the Bugach reservoir (Siberia, Rusia), sampling station 1: $\mathbf{a}-\alpha$-linolenic acid, $\mathbf{b}$ - eicosapentaenoic acid, $\mathbf{c}$ - abundance of alive individuals of Daphnia, $\mathbf{d}$ - non-predatory specific mortality of Daphnia, $\mathbf{e}$ - abundance of alive individuals of adult females of Cyclops vicinus, f - non-predatory specific mortality of adult females of Cyclops vicinus. 1997 - D. cucullata, 1998-2000 - D. longispina 
was small and statistically insignificant $(p>0.05)$, not to mention $\mathrm{R}_{2}$ (thereby, factor loading values were omitted in Table 1). Visual analysis of scatter plots of the correlation matrix did not reveal any non-linearity as a possible cause of the low correlations.

While such independent variables as temperature, $\mathrm{pH}$, concentration of dissolved oxygen, could be regarded as factors of potentially instant effect, factors of food quantity and quality (biomass of different algae taxa) were believed to affect the mortality with a delay. For instance, Luecke and coauthors (1990) have demonstrated that another parameter of zooplankton population dynamics, egg ratios, correlated with edible phytoplankton if egg ratio was lagged by one sampling date. Hence, in the second CCA complex (correlation matrix No. 2) the mortality shifted at week interval relative to biomass of the phytoplankton was used. Results of CCA of the second matrix are given in Table 2. Variance extracted and total redundancy values were low, but higher, than those for correlation matrix No. 1. Canonical correlation, pertained to the first root, $\mathrm{R}_{1}$, was high and statistically significant. Factor loadings and canonical weights of variables for the first canonical root indicated that positive interaction of biomass of green algae with Cyclops NPSM contributed significantly to the overall canonical correlation. Nevertheless, scatter plot of the canonical correlation pertained to the first root (Fig. 3) demonstrated that the high $R_{1}$ value was provided by only one extreme data point.

Additional set of independent variables, potentially related with the mortality (PUFA level), was available for shorter sampling period, 1999-2000. Since the reduction of number of cases (observations) demanded an appropriate reducing of number of variables, the unimportant independent variables, revealed by CCA of the first and second matrixes, were excluded. Thereby, third correlation matrix included the same dependent variables (NPSM of Daphnia and Cyclops) as right set and new independent variables, levels (per cent of total FAs) of 20:5 03 (EPA) and 18:3 03 (ALA) together with biomass of green algae as left set. Cases of the sampling period of 1999-2000 were used. The depended

Table 1. Results of canonical analysis of correlation matrix No. 1 of water temperature, $\mathrm{pH}$, concentration of dissolved oxygen, biomass of cyanobacteria, diatoms, greens and euglens as independent variables (left set) and non-predatory specific mortality of Daphnia and Cyclops as dependent variables (right set) in Bugach reservoir for the sampling periods of 1997-2000

\begin{tabular}{ccc}
\hline & Left set & Right set \\
\hline No. of variables & 7 & 2 \\
Variance extracted (\%) & 28.7 & 100.0 \\
Total redundancy (\%) & 3.8 & 16.7 \\
Number of valid cases & & 34
\end{tabular}

\begin{tabular}{ccc}
\hline & Root 1 & Root 2 \\
\hline Eigenvalues & 0.234 & 0.086 \\
Canonical R & 0.484 & 0.293 \\
Chi-sqr. & 9.0 & 2.5 \\
df & 14 & 6 \\
p & $>0.05$ & $>0.05$ \\
\hline
\end{tabular}


Table 2. Results of canonical analysis of correlation matrix No. 2 of biomass of cyanobacteria, diatoms, greens and euglens as independent variables (left set) and non-predatory specific mortality of Daphnia and Cyclops as dependent variables (right set) in Bugach reservoir for the sampling periods of 1997-2000. The mortality shifted at week interval relative to biomass of the phytoplankton

\begin{tabular}{|c|c|c|}
\hline & Left set & Right set \\
\hline No. of variables & 4 & 2 \\
\hline Variance extracted (\%) & 39.7 & 100.0 \\
\hline Total redundancy (\%) & 11.5 & 25.2 \\
\hline Number of valid cases & \multicolumn{2}{|c|}{37} \\
\hline & Root 1 & Root 2 \\
\hline Eigenvalues & 0.438 & 0.062 \\
\hline Canonical R & 0.661 & 0.248 \\
\hline Chi-sqr. & 20.8 & 2.1 \\
\hline $\mathrm{df}$ & 8 & 3 \\
\hline $\mathrm{p}$ & $<0.01$ & $>0.05$ \\
\hline
\end{tabular}

Factor loadings:

Left set

cyanobacteria

$0.167 \quad-0.381$

diatoms

$-0.141$

$-0.425$

greens

0.949

0.005

euglens

0.116

0.549

Daphnia NPSM

$-0.336$

$-0.942$

Cyclops NPSM

0.950

$-0.313$

Canonical weights:

Left set

cyanobacteria

$-0.263$

$-0.753$

diatoms

0.029

$-0.620$

greens

1.125

$-0.059$

euglens

$-0.171$

0.819

Daphnia NPSM

$-0.313$

$-0.950$

Cyclops NPSM

0.942

$-0.336$ 


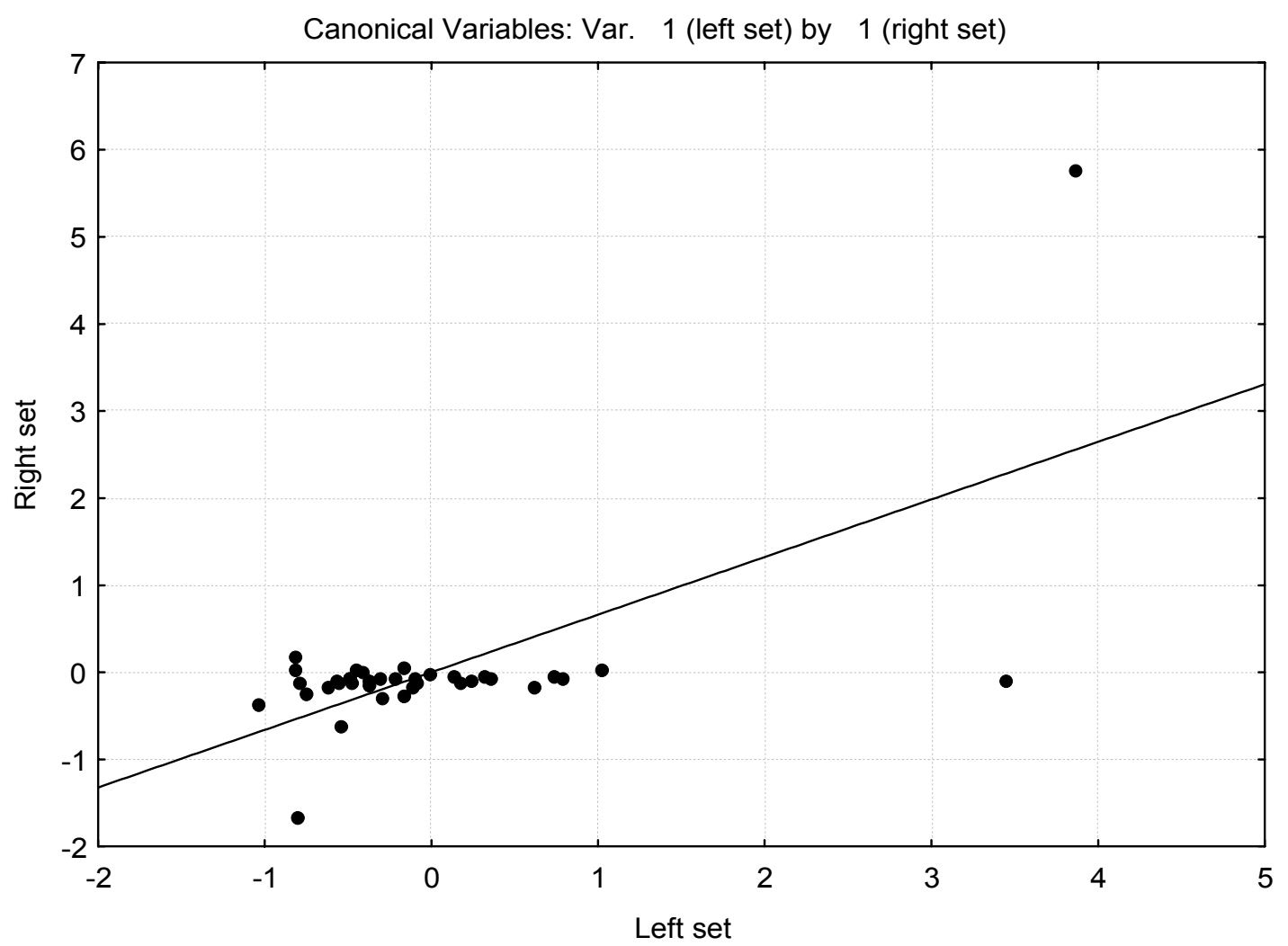

Fig. 3. Plot of correlation between two canonical variables pertained to the first canonical root of correlation matrix No. 2. Matrix No. 2 includes biomass of cyanobacteria, diatoms, greens and euglens as independent variables (left set) and non-predatory specific mortality of Daphnia and Cyclops as dependent variables (right set) in Bugach reservoir for the sampling periods of 1997-2000.

variables also were shifted, like those in correlation matrix No.2.

Percentage of total variance extracted in left set was very high. $\mathrm{R}_{1}$ value was also high, although statistically insignificant (Table 3). These values in general indicate comparatively high interactions between the two sets of variables, but such conclusion needs a following statistical verification. The low statistical significance could be due to the low number of valid cases, and also due to non-linearity of relations between the variables. Indeed, a visual analysis of the scatter plot of the canonical correlation, pertained to the first canonical root, indicates that the relationship seems to be non-linear (Fig. 4). The possible nonlinearity needs the analysis of $\ln$-transformed data, but such transformation would inevitably diminish the number of valid cases because of elimination of zero points, i.e., increase the statistical insignificance. Thus, only paired correlations of appropriate data were available. Since NPSM of Daphnia and EPA level demonstrated the highest factor loadings and canonical weights (Table 3), product-moment correlation was calculated for their ln-transformed values. Scatter plot of these data is given in Fig. 5. The correlation coefficient, $\mathrm{r}=-0.525$, was statistically significant $(\mathrm{p}<0.05)$ at number of pairs 16 . 
Table 3. Results of canonical analysis of correlation matrix No. 3 of two $\omega 3$ PUFAs (percent of total fatty acids) in seston, biomass of greens as independent variables (left set) and non-predatory specific mortality of Daphnia and Cyclops as dependent variables (right set) in Bugach reservoir for the sampling periods of 1999-2000. The mortality shifted at week interval relative to independent variables

\begin{tabular}{|c|c|c|}
\hline & Left set & Right set \\
\hline No. of variables & 3 & 2 \\
\hline Variance extracted $(\%)$ & 73.6 & 100.0 \\
\hline Total redundancy $(\%)$ & 15.4 & 15.2 \\
\hline Number of valid cases & \multicolumn{2}{|c|}{16} \\
\hline & Root 1 & Root 2 \\
\hline Eigenvalues & 0.417 & 0.070 \\
\hline Canonical R & 0.646 & 0.265 \\
\hline Chi-sqr. & 7.3 & 0.9 \\
\hline $\mathrm{df}$ & 6 & 2 \\
\hline $\mathrm{p}$ & $>0.05$ & $>0.05$ \\
\hline
\end{tabular}

Factor loadings:

Left set

$20: 5 \omega 3$

$18: 3 \omega 3$

greens

\section{Daphnia NPSM}

Cyclops NPSM

Canonical weights:

$20: 5 \omega 3$

$18: 3 \omega 3$

greens

Daphnia NPSM

Cyclops NPSM
0.631

0.515

0.473

$-0.649$

0.229

0.762

0.746

0.287

$-1.208$

$-0.284$

0.945
0.754

$-0.846$

0.195

Right set

$-0.761$

$-0.973$

0.555

$-0.686$

0.007

Right set 


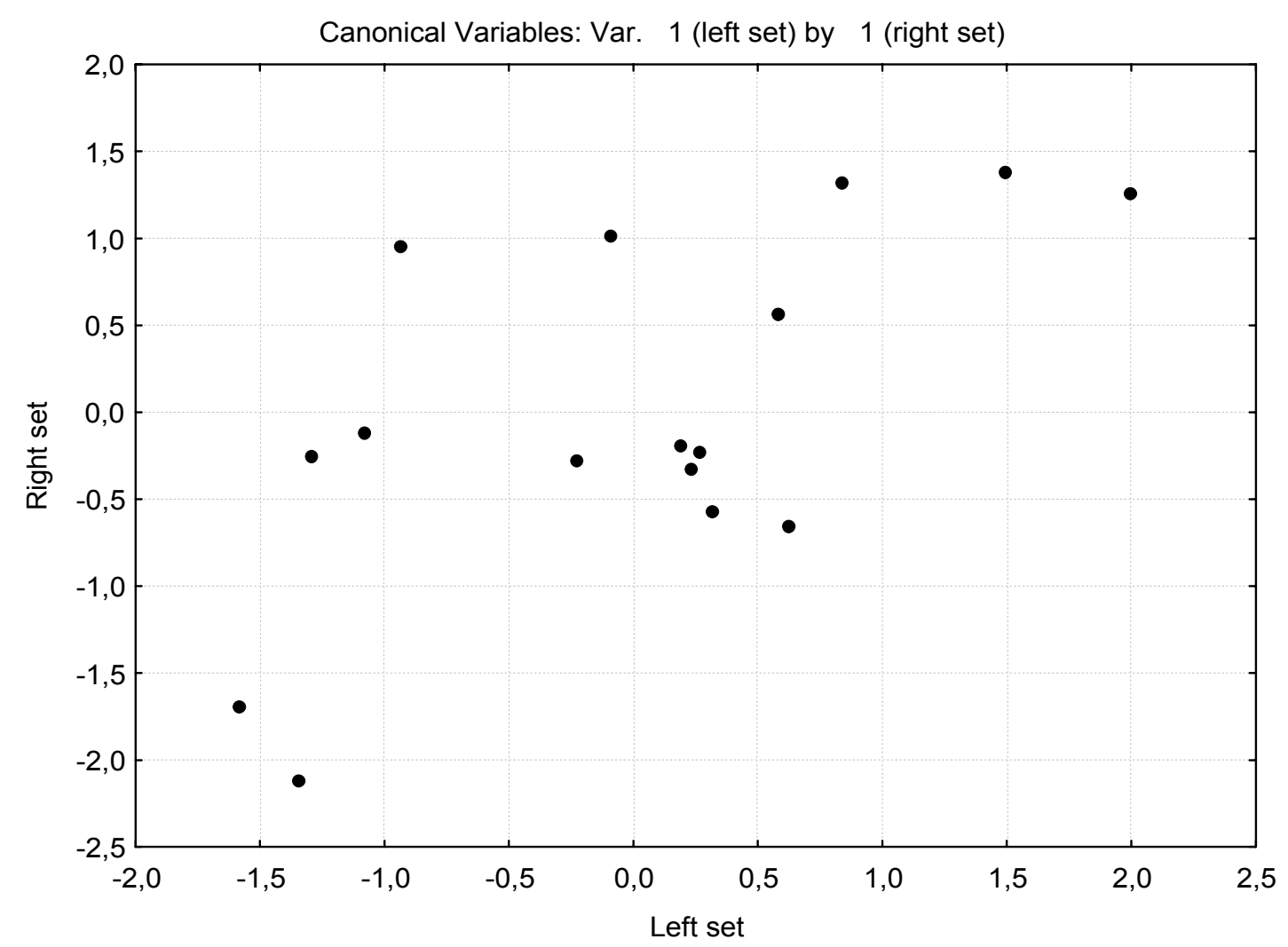

Fig. 4. Plot of correlation between two canonical variables pertained to the first canonical root of correlation matrix No. 3. Matrix No.3 includes percentages of two $\omega 3$ PUFAs (of the total fatty acids) in seston, biomass of greens as independent variables (left set) and non-predatory specific mortality of Daphnia and Cyclops as dependent variables (right set) in Bugach reservoir for the sampling periods of 1999-2000

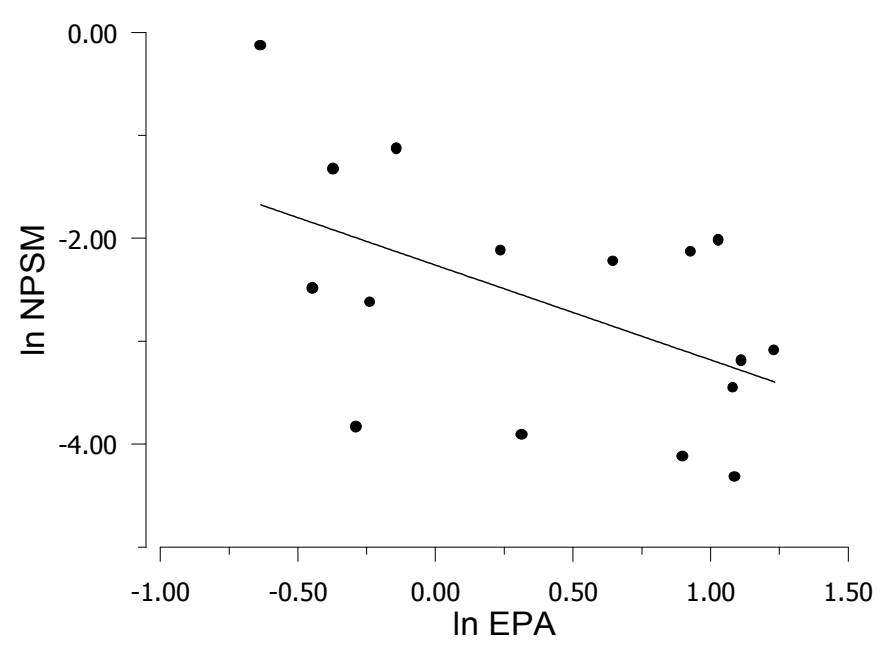

Fig. 5. Correlation between ln of non-predatory specific mortality (NPSM) of Daphnia and ln of level of eicosapentaenoic acid (EPA) in seston in Bugach reservoir (Siberia, Russia). May-October, 1999-2000 


\section{Discussion}

According to detailed estimation of Dorazio (1984) values of mortality due to longevity, i.e. death at some finite age due to physiological senescence are $0.003-0.015$ day $^{-1}$. The nonpredatory mortality of Daphnia in all the seasons was substantial. Its values in many cases (Fig. 2) were higher then values of above-mentioned physiological mortality. Consequently, the obtained NPSM included influence of other different factors of mortality. Besides, our data are in a good agreement with findings of the other authors, who demonstrated a low contribution of fish predation to total Daphnia mortality (Boersma et al., 1996; Mehner et al., 1998; Romare et al., 1999; Hulsmann and Weiler, 2000). Such ecological factors, as water temperature, $\mathrm{pH}$, concentration of dissolved oxygen in the studied site did not influence NPSM value. Evidently, levels of these factors (and their combinations) during the studied period were within limits of tolerance. Biomass of diatoms, cyanobacteria and euglens also did not affect the mortality. Probably, biomass of euglens was on the average too low to influence population of Daphnia. Cyanobacteria, which may exude toxins (e.g., Rohrlack et al., 1999) seem to be harmless in the studied period. Indeed, during toxicological studies in the reservoir (Dubovskaya et al., 2002), besides Daphnia test, a multi-enzyme test, particularly sensitive to cyanobacterial exudations (Kratasyuk et al., 2001) was applied and revealed no toxicity. As to diatoms, it was found earlier (Sushchik et al., 2003), that at least some species had comparatively low nutritive value, i.e., their biomass did not correlate with EPA level in seston. This early observation may explain the absence of correlation between biomass of diatoms and NPSM of Daphnia, revealed in present study.

The most substantial effect on NPSM of Daphnia was produced by EPA level in seston.
At high EPA level the mortality was very small, while at low level of EPA values of NPSM were maximal. The principal importance of EPA for growth of Daphnia is well known (MullerNavarra, 1995; Gulati and DeMott, 1997; MullerNavarra et al., 2000). Our finding is the first evidence that EPA level also influences the nonpredatory mortality.

Besides the negative interaction between EPA level and NPSM of Daphnia, on the basis of CCA of matrix No. 3 it may be concluded, that ALA level and biomass of green algae also tended to contribute negatively to mortality of this zooplankton genus (Table 2, 3). Green algae $<30 \mu \mathrm{m}$ are well known to be suitable food for Daphnia. Thus, it is clear, why a high biomass of green algae, which species were primarily of edible sizes in the studied reservoir, tended to coincide with low mortality. According to some recent data, namely level of $\alpha$-linolenic acid, which is absolutely essential for animals, rather than EPA, can determine growth of some populations of Daphnia (Wacker and von Elert, 2001; von Elert, 2002; Sushchik et al., 2003). The tendency of negative correlation between NPSM and ALA level, revealed in present study, is in a good agreement with the data, mentioned above. Thus, in the studied reservoir main causes of the mortality of Daphnia were food factors.

Nevertheless, the studied causes explained about a half of variance of non-predatory specific mortality of Daphnia. Among the analyzed factors the principal role in this explanation played the food quality, namely EPA level in seston. Meanwhile, a considerable part of variance of NPSM of Daphnia population remained undiscovered. Evidently, some other factors, omitted in our study, e.g., $\mathrm{POC}_{<30 \mu \mathrm{m}}$ concentrations (Hulsmann and Voigt, 2002) or primary production of edible phytoplankton $<30 \mu \mathrm{m}$ (Kamjunke et al., 1999), may likely explain a substantial residual part of the non-predatory mortality variance. This 
assumption may be supported by our finding, that green algae, primarily of edible sizes $<30 \mu \mathrm{m}$, provided significant negative influence on Daphnia mortality value (Table 2), although less substantial than those of EPA and ALA (Table 3).

Besides the food supply, other ecological factors, such as diseases and parasites (Stirnadel and Ebert, 1997; Bittner et al., 2002), also could be the causes of non-predatory mortality. It is interesting to remark, that a study of epibiontic microalgae of Daphnia in the Bugach reservoir (Dubovskaya et al., 2005) revealed, that the epibionts did not increase non-predatory mortality of the zooplankton, but could increase namely predatory mortality, since individuals covered with colored microalgae, were more conspicuous and vulnerable for planktivorous fish (Willey et al., 1990; 1993). The Bugach reservoir is inhabited by several species of planktivorous fish, among them Carassius auratus Linnaeus, Leucaspius delineatus Heckel are rather numerous (Gladyshev et al., 2003b). Nevertheless, bacterial or viral species-specific infection also may be one of causes of non-predatory mortality (Gries and Gude, 1999).

Concerning Cyclops we suppose that causes of mortality of this species remain unrevealed, since results of CCA of matrix No. 2 were ambiguous. If assume, that the extreme point (Fig. 3), provided the high value of the correlation coefficient, was valid rather than accidental, this would mean positive direct influence of an increase of biomass of green algae on an increase of mortality of Cyclops (Table 2). Such influence looks like doubtful. Although cyclopoids may not utilize some hard-walled green algae due to lack of cellulase in their guts, C. vicinus was proven to survive and develop on a pure algal diet, included greens (Hansen and Santer, 1995). Moreover, results of CCA of matrix No. 3 demonstrated that in absence of the extreme point there was no significant influence of biomass of greens on NPSM of Cyclops, neither on the basis of factor loadings nor canonical weights (Table 3 ). It should be remarked, that the mortality of Cyclops in the reservoir on the average was substantially higher (Fig. 2f), than that in laboratory conditions, 0.001-0.014 day ${ }^{-1}$, obtained by Hansen and Santer (1995). We believe that some peaks of adult Cyclops NPSM may be the result of physiological aging after reproductive period, but the others may be caused by different factors, particularly by diseases and parasites, omitted in our study.

\section{Conclusion}

In summary, a decrease of food quality, namely EPA level in seston, resulted in increase of non-predatory mortality of Daphnia, and about $50 \%$ of variance of NPSM could be attributed to this factor. At the same time, considerable part of NPSM variance for Daphnia and all the variance of NPSM of $C$. vicinus stay to be revealed in a future on the basis of other ecological factors, rather than those considered in present study.

\section{Acknowledgements}

The work was supported by joint grant of the U.S. Civilian Research \& Development Foundation for the Independent States of the Former Soviet Union (CRDF) and Ministry of Education of Russian Federation No. KY-002$\mathrm{X} 1$. At the stage of generalisation the work was also supported by Russian Foundation for Basic Research Grant No. 05-04-48423. I am grateful to M.I. Gladyshev, N.N. Sushchik, E.S. Kravchuk and E.A. Ivanova for providing essential data and help in all stages of the work. 


\section{References}

Bec A., Desvilettes Ch., Vera A., Fontvielle D., Bourdier G. (2003) Nutritional value of different food sources for the benthic Daphnidae Simocephalus vetulus: role of the fatty acids. Arch. Hydrobiol. 156: $145-163$.

Bittner K., Rothhaupt K.-O., Ebert D. (2002) Ecological interactions of the microparasite Caullerya mesnili and its host Daphnia galeata. Limnol. Oceanogr. 47: 300-305.

Boersma M., van Tongeren O.F.R., Mooij W.M. (1996) Seasonal patterns in the mortality of Daphnia species in a shallow lake. Can. J. Fish. Aquat. Sci. 53: 18-28.

Dorasio R.M. (1984) The contribution of longevity to population death rates. Hydrobiologia 108: 239-243.

Dubovskaya O.P., Gladyshev M.I., Gubanov V.G. (1999) Seasonal dynamics of number of alive and dead zooplankton in a small pond and some variants of mortality estimation. Zh. Obshch. Biol. (J. of General Biology) 60: 543-555. (translated into English).

Dubovskaya O.P., Gladyshev M.I., Esimbekova E.N., Morozova I.I., Gold Z.G., Makhutova O.N. (2002) Study of possible relation between seasonal dynamics of zooplankton non-consumptive mortality and water toxicity in a pond. Biologiia Vnutrennih Vod (Biology of Inland Waters) 3: 39-43. (in Russian).

Dubovskaya O.P., Gladyshev M.I., Gubanov V.G., Makhutova O.N. (2003) Study of nonconsumptive mortality of Crustacean zooplankton in a Siberian reservoir using staining for live/dead sorting and sediment traps. Hydrobiologia 504: 223-227.

Dubovskaya O.P., Klimova E.P., Kolmakov V.I., Gaevsky N.A., Ivanova E.A. (2005) Seasonal dynamic of phototrophic epibionts on crustacean zoolankton in a eutrophic reservoir with cyanobacterial bloom. Aquatic Ecology 39: 167-180.

Gladyshev M.I. (1993) A device for staining of zooplankton in order to allow live/dead sorting of preserved samples. Gidrobiologicheskii Zhurnal 2: $94-97$ (translated into English).

Gladyshev M.I., Dubovskaya O.P., Gubanov V.G., Makhutova O.N. (2003a) Evaluation of nonpredatory mortality of two Daphnia species in a Siberian reservoir. J. Plankton Res. 25: 999-1003.

Gladyshev M.I., Gribovskaya I.V., Moskvichova A.V., Muchkina E.Y., Chuprov S.M., Ivanova E.A. (2001) Content of metals in compartments of ecosystem of a Siberian pond. Arch. Envir. Contaminat. Toxicol. 41: 157-162.

Gladyshev M.I., Emelianova A.Y., Kalachova G.S., Zotina T.A., Gaevsky N.A., Zhilenkov M.D. (2000) Gut content analysis of Gammarus lacustris from Siberian lake using biochemical and biophysical methods. Hydrobiologia 431: 155-163.

Gladyshev M.I., Chuprov S.M., Kolmakov V.I., Dubovskaya O.P., Zadorin A.A., Zuev I.V., Ivanova E.A. \& Kravchuk E.S. (2003b) Biomanipulation round the trophic cascade at a small reservoir. Doclady Akademii Nauk 390: 276-277.

Gries T., Gude H. (1999) Estimates of the nonconsumptive mortality of mesozooplankton by measurement of sedimentation losses. Limnol. Oceanogr. 44: 459-465.

Gulati R.D., DeMott W.R. (1997) The role of food quality for zooplankton: remarks on the stateof-the-art, perspectives and priorities. Freshwater Biol. 38: 753-768. 
Hansen A.-M., Santer B. (1995) The influence of food resources on the development, survival and reproduction of the two cyclopoid copepods: Cyclops vicinus and Mesocyclops leuckarti. J. Plankton Res. 17: 631-646.

Hulsmann S., Mehner T., Worischka S., Plewa M. (1999) Is the difference in population dynamics of Daphnia galeata in littoral and pelagic areas of a long-term biomanipulated reservoir affected by age-0 fish predation? Hydrobiologia 408/409: 57-63.

Hulsmann S., Voigt H. (2002) Life history of Daphnia galeata in a hypertrophic reservoir and consequences of non-consumptive mortality for the initiation of a midsummer decline. Freshwater Biol. 47: 2313-2324.

Hulsmann S., Weiler W. (2000) Adult, not juvenile mortality as a major reason for the midsummer decline of a Daphnia population. J. Plankton Res. 22: 151-168.

Jeffers J. (1981) An introduction to system analysis: with ecological application. Mir, Moscow, 252 p. (translated from English).

Kamjunke N., Benndorf A., Wilbert C., Opitz M., Kranich J., Bollenbach M., Benndorf J. (1999) Bacteria ingestion by Daphnia galeata in a biomanipulated reservoir: a mechanism stabilizing biomanipulation? Hydrobiologia 403: 109-121.

Kratasyuk V.A., Esimbekova E.N., Gladyshev M.I., Khromichek E.B., Kuznetsov A.M., Ivanova E.A. (2001) The use of bioluminescent biotests for study of natural and laboratory aquatic ecosystems. Chemosphere 42: 909-915.

Luecke C., Vanni M.J., Magnuson J.J., Kitchell J.F., Jacobson P. (1990) Seasonal regulation of Daphnia populations by planktivorous fish: Implication for the spring clear-water phase. Limnol. Oceanogr. 35: 1718-1733.

Mehner T., Hulsmann S., Worischka S., Plewa M., Benndorf J. (1998) Is the midsummer decline of Daphnia really induced by age-0 fish predation? Comparison of fish consumption and Daphnia mortality and life history parameters in a biomanipulated reservoir. J. Plankton Res. 20: 1797-1811.

Muller-Navarra D. (1995) Evidence that a highly unsaturated fatty acid limits Daphnia growth in nature. Arch. Hydrobiol. 132: 297-307.

Muller-Navarra D.C., Brett M.T., Liston A.M., Golgman Ch.R. (2000) A highly unsaturated fatty acid predicts carbon transfer between primaty producers and consumers. Nature 403: 74-77.

Polishchuk L.V., Ghilarov A.M. (1981) Comparison of two approaches used to calculate zooplankton mortality. Limnol. Oceanogr. 26: 1162-1168.

Razlutskij V.I. (1996) Evaluation of population parameters of Cladocera. Gidrobiologichesskii Zhurnal 3: 26-33 (translated into English).

Rohrlack T., Henning M., Kohl J.-G. (1999) Does the toxic effect of Microcystis aeruginosa on Daphnia galeata depend on microcystin ingestion rate? Arch. Hydrobiol. 146: 385-395.

Romare P., Bergman E., Hansson L.-A. (1999) The impact of larvae and juvenile fish on zooplankton and algal dynamics. Limnol. Oceanogr. 44: 1655-1666.

Seepersad B., Crippen R.W. (1978) Use of aniline blue for distinguishing between live and dead freshwater zooplankton. J. Fish. Res. Board Canada 35: 1363-1366.

Stirnadel H.A., Ebert D. (1997) Prevalence, host specificity and impact on host fecundity of microparasites and epibionts in three sympatric Daphnia species. J. Animal Ecol. 66: 212-222. 
Sushchik N.N., Gladyshev M.I., Kalachova G.S., Kravchuk E.S., Dubovskaya O.P., Ivanova E.A. (2003) Particulate fatty acids in two small Siberian reservoirs dominated by different groups of phytoplankton. Freshwater Biol. 48: 394-403.

Velimirov B. (1991) Detritus and the concept of non-predatory loss. Arch. Hydrobiol. 121: 1-20.

Von Elert E. (2002) Determination of limiting polyunsaturated fatty acids in Daphnia galeata using a new method to enrich food algae with single fatty acids. Limnol. Oceanogr. 47: 1764-1773.

Wacker A., von Elert E. (2001) Polyunsaturated fatty acids: evidence for non-substitutable biochemical resources in Daphnia galeata. Ecology 82: 2507-2520.

Willey R.L., Cantrell P.A., Threlkeld S.T. (1990) Epibiotic euglenoid flagellates increase the susceptibility of some zooplankton to fish predation. Limnol. Oceanogr. 35: 952-959.

Willey R.L., Willey R.B, Threlkeld S.T. (1993) Planktivore effects on zooplankton epibiont communities: Epibiont pigmentation effects. Limnol. Oceanogr. 38: 1818-1822.

Wojtal A., Frankiewicz P., Zalewski M. (1999) The role of invertebrate predator Leptodora kindti in the trophic cascade of a lowland reservoir. Hydrobiologia 416: 215-233. 